\title{
Amplitude-Integrated Electroencephalography and Brain Oxygenation for Postcardiac Arrest Patients with Targeted Temperature Management
}

\author{
Shingo Ihara, MD, PhD, Atsushi Sakurai, MD, PhD, Kosaku Kinoshita, MD, PhD, \\ Junko Yamaguchi, MD, PhD, and Atsunori Sugita, MD, PhD
}

Brain injury is the most common cause of death postcardiac arrest. Amplitude-integrated electroencephalography (aEEG) is suggested to be useful in the prognostication in cases of postcardiac arrest brain injury. However, combined monitoring with aEEG and regional oxygen saturation $\left(\mathrm{rSO}_{2}\right.$ ) for postcardiac arrest syndrome (PCAS) patients to improve accuracy has not been reported. The purpose of this prospective observational study is to assess the usefulness of aEEG and $\mathrm{rSO}_{2}$ for PCAS patients with targeted temperature management (TTM) to predict neurological outcome and possibly identify the pathophysiology of postcardiac arrest brain injury. PCAS patients with TTM at $34^{\circ} \mathrm{C}$ were monitored by aEEG and $\mathrm{rSO}_{2}$ immediately after admission to the intensive care unit and evaluated at the start of monitoring, and 24 and 48 hours after return of spontaneous circulation (ROSC). Patients were divided into two groups according to electroencephalography (EEG) pattern: a continuous EEG (C) pattern group and a noncontinuous EEG (NC) pattern group. Patients with $\mathrm{C}$ pattern had a significantly more favorable neurologic outcome compared with patients with an NC pattern at each point in time. No significant difference in $\mathrm{rSO}_{2}$ values was observed between the $\mathrm{C}$ pattern and the $\mathrm{NC}$ pattern at any time point. Variation coefficient at $\mathrm{rSO}_{2}$ in the $\mathrm{NC}$ group was significantly greater than that in the $\mathrm{C}$ group from the start of the monitoring to 24 hours. aEEG is useful in predicting outcome for PCAS patients whereas $\mathrm{rSO}_{2}$ is not.

Keywords: aEEG, $\mathrm{rSO}_{2}$, out-of-hospital cardiac arrest, targeted temperature management, outcome

\section{Introduction}

D ESPITE RECENT MEDICAL ADVANCES, the outcome of patients resuscitated from cardiac arrest is still very poor. In Japan, $87 \%$ of patients experiencing cardiac arrest outside of the hospital died and even in cases of witnessed arrest and with cardiac etiology, only $9 \%$ achieved a good neurological outcome (SOS-KANTO 2012 Study Group, 2015). The International Liaison Committee on Resuscitation defined causes of postcardiac arrest syndrome (PCAS) into four types of pathophysiology: postcardiac arrest brain injury, postcardiac arrest myocardial dysfunction, systemic ischemia/reperfusion response, and persistent precipitating pathology (Nolan et al., 2008). Among these pathophysiology types, postcardiac arrest brain injury is the most common cause of death (Dragancea et al., 2013), and it greatly disrupts rehabilitation in cases of PCAS patients who survive. Therefore, investigation of brain injury for PCAS patients can be considered one of the most important and crucial approaches to improve outcome. Usually, PCAS pa- tients are treated with targeted temperature management (TTM) in the intensive care unit (ICU) (Callaway et al., 2015). In this situation in the ICU, several kinds of neuromonitoring modalities, such as electrophysiology, intracranial pressure measurements, and brain oxygenation, are suggested to be useful in the prognostication and illustration of the pathophysiology in cases of postcardiac arrest brain injury (Reis et al., 2017).

Rundgren et al. (2006, 2010) reported that amplitudeintegrated electroencephalography (aEEG) is useful to predict neurological outcomes for PCAS patients with TTM. In these studies, aEEG measured with PCAS patients was divided into the following four patterns: continuous, flat, burst suppression (BS), and electrographic status epilepticus (ESE). Patients with continuous pattern tended to have a favorable neurological outcome whereas those with BS or ESE tended to have an unfavorable neurological outcome. Neurological outcome of initial flat patterns was difficult to predict, because some flat patterns changed to continuous patterns during TTM and became favorable neurological

Division of Emergency and Critical Care Medicine, Department of Acute Medicine, Nihon University School of Medicine, Tokyo, Japan.

(C) Shingo Ihara et al., 2019; Published by Mary Ann Liebert, Inc. This Open Access article is distributed under the terms of the Creative Commons License (http://creativecommons.org/licenses/by/4.0), which permits unrestricted use, distribution, and reproduction in any medium, provided the original work is properly cited. 
outcomes. These facts indicated that the electrophysiological situation in postcardiac arrest brain injury was associated with the severity of brain damage and might change over time.

Brain oxygenation status between circulation and metabolism can be measured by regional oxygen saturation $\left(\mathrm{rSO}_{2}\right)$ using the near-infrared spectroscopy (NIRS) method. NIRS is a noninvasive method used to monitor PCAS patients. Three studies reported that regional cerebral oxygenation of PCAS patients with good outcome was significantly better compared with those with poor outcome (Meex et al., 2013; Ahn et al., 2014; Storm et al., 2014), although one study did not show any such association (Ibrahim et al., 2015). Further investigation to clarify the pathophysiology of postcardiac arrest brain injury, through monitoring by $\mathrm{rSO}_{2}$ at the ICU, is needed.

One study reported $\mathrm{rScO}_{2}$ and aEEG measurements for infants with perinatal asphyxia (Lemmers et al., 2013). However, combined monitoring with aEEG and $\mathrm{rSO}_{2}$ for adult PCAS patients with TTM has not been reported. The aim of this study was to assess aEEG and $\mathrm{rSO}_{2}$ of PCAS patients with TTM, which may be useful in predicting neurological outcome and may illustrate the pathophysiology of postcardiac arrest brain injury.

\section{Methods}

\section{Patients}

This prospective observational study was performed at the ICU at Nihon University Itabashi Hospital. Approval was obtained from the Clinical Research Institutional Review Board (IRB) of Nihon University School of Medicine Itabashi Hospital (RK-121109-1). This study included comatose survivors of out-of-hospital PCAS patients aged 20 years or older who were treated with TTM from July 1, 2012 to June 31, 2015. This study included consecutive patients with TTM, but patients were excluded in cases of (1) death within 72 hours after cardiac arrest, (2) history of neurodegenerative disease, or (3) severe traumatic brain injury. Among patients who received TTM, patient characteristics of age, gender, cause of cardiac arrest, witness, shockable rhythm, bystander cardiopulmonary resuscitation (CPR), and mortality between included and excluded patients in this study were compared.

\section{TTM protocol}

Patients who remained comatose after return of spontaneous circulation (ROSC) were treated with TTM at $34^{\circ} \mathrm{C}$ for 24 hours. Exclusion criteria of TTM included hemodynamic instability refractory to the use of vasopressor agents, respiratory failure $\left(\mathrm{PaO}_{2} / \mathrm{FiO}_{2}<200\right)$, and terminal illness before cardiac arrest. After ROSC, patients were sedated (midazolam, $0.08 \mathrm{mg} / \mathrm{kg}$ intravenously) and paralyzed (rocuronium, $0.8 \mathrm{mg} / \mathrm{kg}$ intravenously) for shivering control, followed by continuous infusion of midazolam (0.05$0.1 \mathrm{mg} / \mathrm{kg} / \mathrm{h})$, fentanyl $(1 \mu \mathrm{g} / \mathrm{kg} / \mathrm{h})$, and rocuronium $(0.3-$ $0.6 \mathrm{mg} / \mathrm{kg} / \mathrm{h})$. Hypothermia was induced by cold saline $\left(4^{\circ} \mathrm{C}\right.$ $30 \mathrm{~mL} / \mathrm{kg}$ ) and a surface cooling device (Arctic Sun system, Medivance, Louisville, CO) for the maintenance of TTM. Thereafter, patients were rewarmed at a maximum of $0.1^{\circ} \mathrm{C} / \mathrm{h}$ to normothermia. Targeted management parameters were as follows: mean blood pressure (BP) $>65 \mathrm{mmHg}, \mathrm{SpO}_{2}>94 \%$ to $<97 \%, \mathrm{PaCO}_{2}>35$ to $<45 \mathrm{mmHg}$, and hemoglobin $(\mathrm{Hb})$ $>7 \mathrm{~g} / \mathrm{dL}$.

\section{aEEG and $\mathrm{rSO}_{2}$ monitoring and analysis}

All patients were monitored with an aEEG (NicoletOne; Cardinal Health, Dublin, OH) and $\mathrm{rSO}_{2}$ (INVOS $5100 \mathrm{C}$; Covidien, Boulder, $\mathrm{CO}$ ) as soon as possible after arrival at the ICU. The aEEG was examined by using six subdermal electrodes in the left frontal (F3), right frontal (F4), left parietal $(\mathrm{P} 3)$, and right parietal $(\mathrm{P} 4)$ positions with ground in the frontal midline and reference in the central midline. The NIRS probes were placed on the left side forehead of each patient to detect frontal cerebral oxygen saturation. aEEG patterns were classified into four categories: continuous, flat, BS, and ESE, as previously described by Rundgren (Rundgren et al., 2006, 2010). aEEG, $\mathrm{rSO}_{2}$, and parameters (mean $\mathrm{BP}, \mathrm{SpO}_{2}, \mathrm{PaCO}_{2}, \mathrm{Hb}$, and body temperature) were evaluated at the start of the monitoring, and 24 and 48 hours after ROSC. Patients were divided into two groups according to electroencephalography (EEG): a continuous EEG (C) pattern group and a noncontinuous EEG (NC) pattern group. The $\mathrm{C}$ pattern group was determined by a continuous aEEG pattern, and the NC pattern group was determined by a flat, $\mathrm{BS}$, or ESE aEEG pattern.

\section{Outcome assessment}

Neurological outcome was assessed by using the Cerebral Performance Category (CPC) scale by the ICU physician at the time of discharge from Nihon University School of Medicine Itabashi Hospital (Cummins et al., 1991). Favorable neurologic outcome was defined as a CPC score of 1 or 2 , and unfavorable outcome was defined as a CPC score of 3-5.

\section{Statistical analysis}

Statistical analysis was performed by using SPSS (IBM SPSS Version22). Fisher's exact probability test, $t$-test, and Mann-Whitney $U$ test were used to determine statistical significance. Range of variation within $\mathrm{rSO}_{2}$ was evaluated by the coefficient of variation [CV: (standard deviation/mean) $\times 100$ ]. Significant difference at $\mathrm{CV}$ between the two groups was calculated by the likelihood ratio test based on the hypothesis that $\mathrm{k}$ normally distributed populations share the same CV (Verrill and Johnson, 2007). Probability values of $p<0.05$ were considered statistically significant.

\section{Results}

During the study period, 1266 out-of-hospital cardiac arrest (OHCA) patients were admitted to the hospital and 375 of these had ROSC. One hundred and fifty patients received TTM, and 49 patients were monitored by using aEEG and $\mathrm{rSO}_{2}$. One hundred and one patients were excluded due to lack of measurement instruments $(n=79)$, hemodynamic instability during TTM (18), consent not obtained (3), and operation for pulmonary embolism (1). Twenty-one patients did not improve consciousness and died. There was no patient withdrawal. Table 1 shows patient characteristics. The age of all patients was $64.7 \pm 16.0$ (mean \pm standard deviation [SD]) years old, and monitoring was initiated at a median time of $351 \pm 182$ minutes after ROSC. Comparing the two groups, the ratio of men was significantly larger and the time interval 
Table 1. Comparison of Patient Characteristics Between Patients with C and NC Patterns

\begin{tabular}{|c|c|c|c|c|}
\hline & All patients $(\mathrm{n}=49)$ & $C$ pattern $(\mathrm{n}=13)$ & NC pattern $(\mathrm{n}=36)$ & $\mathrm{p}$ \\
\hline Age, years, mean $\pm S D$ & $64.7 \pm 16.0$ & $64.0 \pm 13.9$ & $64.9 \pm 16.9$ & 0.642 \\
\hline Male, $n(\%)$ & $29(59.2)$ & $11(84.6)$ & $18(50.0)$ & 0.047 \\
\hline Cardiac cause, $n(\%)$ & $28(57.1)$ & $9(69.2)$ & $19(52.8)$ & 0.348 \\
\hline Witnessed, $n(\%)$ & $37(75.5)$ & $11(84.6)$ & $26(72.2)$ & 0.474 \\
\hline Shockable rhythm, $n(\%)$ & $18(36.7)$ & $6(46.2)$ & $12(33.3)$ & 0.325 \\
\hline Bystander CPR, $n(\%)$ & $25(51.0)$ & $10(76.9)$ & $15(41.7)$ & 0.051 \\
\hline Time from arrest to ROSC, minute, mean \pm SD & $31.7 \pm 19.7$ & $15.6 \pm 14.8$ & $37.4 \pm 18.1$ & 0.001 \\
\hline $\begin{array}{l}\text { Time from ROSC to aEEG and } \mathrm{rSO}_{2} \\
\text { application, minute, mean } \pm \mathrm{SD}\end{array}$ & $351.0 \pm 182.4$ & $365.8 \pm 192.0$ & $345.6 \pm 181.3$ & 0.667 \\
\hline
\end{tabular}

aEEG, amplitude-integrated electroencephalography; C pattern, continuous EEG pattern; CPR, cardiopulmonary resuscitation; NC pattern, noncontinuous EEG pattern; ROSC, return of spontaneous circulation; $\mathrm{rSO}_{2}$, regional oxygen saturation; $\mathrm{SD}$, standard deviation.

from arrest to ROSC was significantly smaller in the $\mathrm{C}$ pattern group than in the NC pattern group. Characteristics of the 80 excluded patients with TTM (lack of measurement instruments and operation for pulmonary embolism) were: mean age 62.0 years, ratio of males was $47.5 \%$, cardiac cause $56.2 \%$, witness $60.0 \%$, shockable rhythm $31.3 \%$, bystander CPR $53.8 \%$, and favorable neurological outcome $31.3 \%$. Regarding characteristics of the 49 included patients and those of the 80 excluded patients with TTM, no statistically significant difference was observed.

No significant difference between the parameters of the $\mathrm{C}$ pattern group and the NC pattern group was observed, except for $\mathrm{Hb}$ at the start of the measurement (C vs. NC; 14.0土 $1.7 \mathrm{~g} / \mathrm{dL}$ vs. $12.4 \pm 3.3 \mathrm{~g} / \mathrm{dL}, p=0.041)$ and after 48 hours $(13.3 \pm 3.0 \mathrm{~g} / \mathrm{dL}$ vs. $10.8 \pm 2.4 \mathrm{~g} / \mathrm{dL} ; p=0.020)$, and mean BP after 24 hours $(99.8 \pm 17.9 \mathrm{mmHg}$ vs. $86.8 \pm 18.9 \mathrm{mmHg}$, $p=0.019)$. Similar results were found when parameters of patients with $\mathrm{C}$ patterns were compared with flat patterns.

At the start of the monitoring, the $\mathrm{C}$ pattern group was observed in 13 out of 49 patients, 11 of whom had favorable neurologic outcomes. The NC pattern group was observed in 36 patients (flat 26, BS 9, ESE 1), 4 of whom had favorable neurologic outcomes. At 24 hours after ROSC, the $\mathrm{C}$ pattern group was seen in 18 of 49 patients, 15 of whom had favorable neurologic outcomes. Thirty-one patients of the NC pattern group (flat 17, BS 12, ESE 2) did not have favorable neurologic outcomes. These results were similar to those at 24 hours after ROSC and at 48 hours (Fig. 1). Significantly favorable neurologic outcomes were observed for the $\mathrm{C}$ pattern group compared with the $\mathrm{NC}$ pattern group at all times (Fig. 2). At the start of the monitoring, the $\mathrm{C}$ pattern group showed sensitivity at $73.3 \%$ (95\% confidence interval [CI], 55.1-82.4), specificity 94.1\% (95\% CI, 86.1-98.1), positive predictive value $84.6 \%$ (95\% CI, 63.6-95.1), negative predictive value $88.9 \%$ (95\% CI, 81.3-92.7), and odd ratio 44.0 (95\% CI, 7.6-246.3) for favorable neurologic outcomes. Similar results were obtained after 24 and 48 hours with sensitivity $100 \%$ (95\% CI, 84.8-100), specificity $91.2 \%$ (95\% CI, 84.5-91.2), positive predictive value $83.3 \%$ (95\% CI, 70.7-83.3), and negative predictive value $100 \%$ (95\% CI, 92.7-100) (Table 2). C pattern was observed in all patients with favorable neurologic outcomes by 24 hours from ROSC.

No significant difference in $\mathrm{rSO}_{2}$ values was observed between the $\mathrm{C}$ pattern group and the $\mathrm{NC}$ pattern group at all points in time (Fig. 3a). $\mathrm{CV}$ at $\mathrm{rSO}_{2}$ in the $\mathrm{NC}$ group was significantly greater than that in the $\mathrm{C}$ group at the start of the monitoring and 24 hours after ROSC (Fig. 3b). Regarding $\mathrm{CV}$, no significant differences in parameters between $\mathrm{C}$ pattern and NC pattern groups were observed, except $\mathrm{Hb}$ at the start of measuring (C vs. NC: 12.4 vs. 26.6, $p=0.0029$ ).

Five patients who initially had a flat pattern changed to the $\mathrm{C}$ pattern group and 21 patients remained in the NC pattern

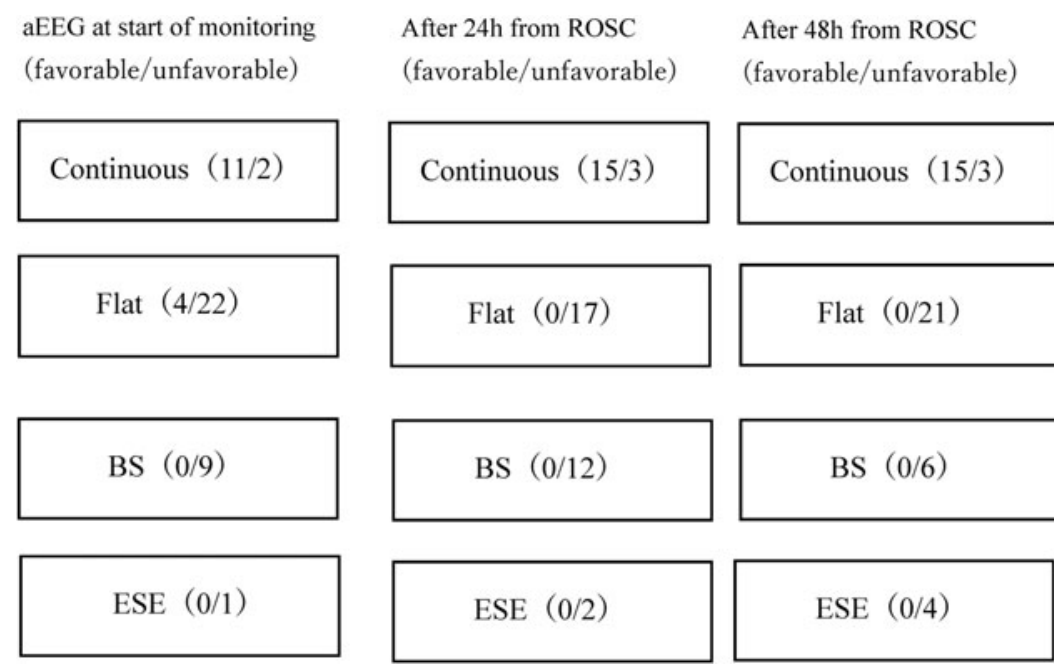

FIG. 1. aEEG from the start of the monitoring to after 48 hours from ROSC monitoring (favorable/unfavorable). aEEG, amplitude-integrated electroencephalography; ROSC, return of spontaneous circulation. 
FIG. 2. The C pattern group had a significantly more favorable neurologic outcome compared with the NC pattern group for all points in time. $\mathrm{C}$ group, continuous EEG group; NC group, noncontinuous EEG group.

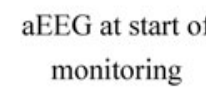

Time from ROSC

$24 \mathrm{~h}$

$48 \mathrm{~h}$

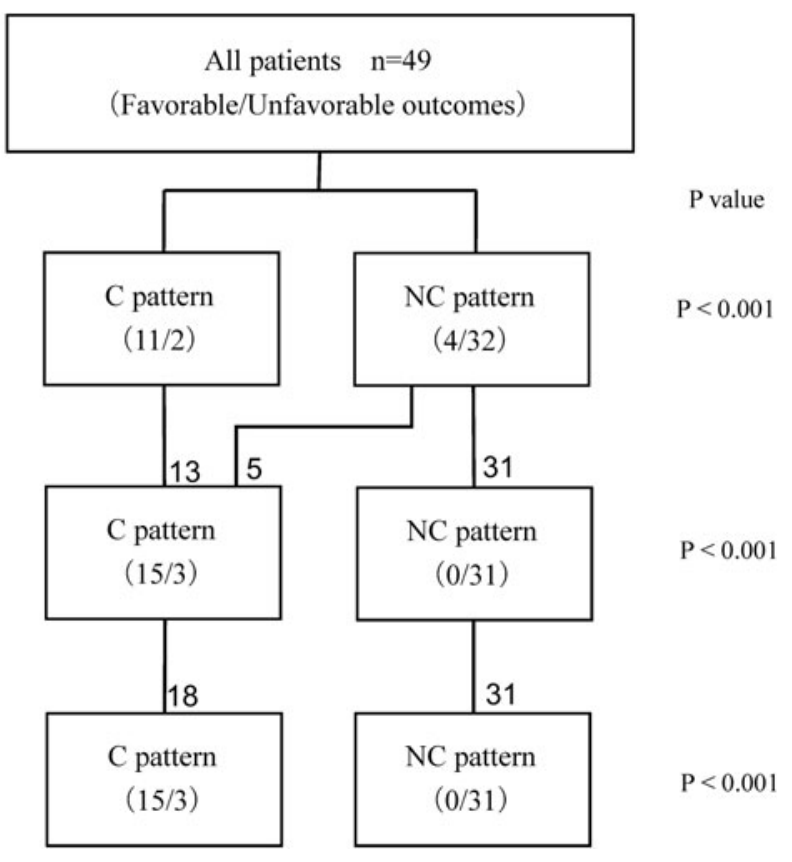

group at 24 and 48 hours after ROSC. Four out of five cases of $\mathrm{C}$ patterns showed favorable neurological outcomes at 24 and 48 hours after ROSC. All 21 patients with an NC pattern had an unfavorable neurological outcome at 24 and 48 hours after ROSC. The $\mathrm{rSO}_{2}$ values between the two groups were compared, and no significance difference at any point in time was observed at the start of the measurement (flat to $\mathrm{C}$ pattern vs. flat to NC pattern; $54.3 \% \pm 6.2 \%$ vs. $57.9 \% \pm 12.5 \%, p=0.408)$, after 24 hours $(61.5 \% \pm 12.6 \%$ vs. $58.3 \% \pm 9.7 \%, p=0.408)$ and after 48 hours $(69.0 \% \pm 14.1 \%$ vs. $60.3 \% \pm 11.3 \%$, $p=0.245)$.

\section{Discussion}

An initial $\mathrm{C}$ pattern or an evolution into $\mathrm{C}$ pattern was strongly associated with favorable neurological outcomes. An BS pattern or ESE at any time was associated with unfavorable neurological outcomes. There were no differences in $\mathrm{rSO}_{2}$ between the $\mathrm{C}$ pattern group and the $\mathrm{NC}$ pattern group at any time point.

In this study, patients with a $\mathrm{C}$ pattern on aEEG from an early stage had a favorable neurological outcome. Time interval from arrest to ROSC was significantly shorter for the $\mathrm{C}$ pattern group than that for the NC pattern group. This time interval indicates brain ischemic time and intensity of brain injury (Komatsu et al., 2014). These facts suggested that in cases where the $C$ pattern could be observed at the early phase after ROSC in PCAS patients, postcardiac arrest brain injury would be mild. However, outcome for patients with a flat pattern within 24 hours after ROSC was difficult to predict, as the pattern may change other patterns over time. Rundgren et al. (2010) classified the aEEG waveform into 4 patterns and reported that the 29 out of 32 patients with an initial waveform of continuous pattern had a favorable neurological outcome. In this study, to more conveniently evaluate the aEEG pattern, it was classified into two types, C pattern and NC pattern. aEEG monitoring started $\sim 6$ hours from ROSC on average. When aEEG at that time was $\mathrm{C}$ pattern, favorable neurological outcome could be predicted with an accuracy of positive predictive value of $84.6 \%$. Moreover, unless a patient showed a $\mathrm{C}$ pattern within 24 hours after ROSC, the patient had an unfavorable outcome. aEEG is useful in predicting outcome for PCAS patients, and accuracy of outcome prediction is improved by measuring aEEG over time.

The NC group is composed of flat, BS, and ESE patterns. BS and ESE were reported as unfavorable outcomes. Bassetti et al. (1996) reported the Hockaday classification, which are EEG classifications of cases after cardiac arrest. Among this classification, BS was classified as Grade IV and was reported to be associated with an unfavorable outcome (Bassetti et al., 1996). In this study, patients with BS at any time points had an unfavorable outcome. Therefore, brain injury in patients with BS pattern is considered severe.

Table 2. C Group Validity for Favorable Neurological Outcomes at Each Time Point

\begin{tabular}{|c|c|c|c|c|c|}
\hline & $\begin{array}{l}\text { Sensitivity \% } \\
(95 \% \text { CI })\end{array}$ & $\begin{array}{l}\text { Specificity \% } \\
(95 \% \text { CI })\end{array}$ & $\begin{array}{c}\text { Positive predictive } \\
\text { value }(95 \% \text { CI) }\end{array}$ & $\begin{array}{c}\text { Negative predictive } \\
\text { value }(95 \% \mathrm{CI})\end{array}$ & Odds ratio \\
\hline $\begin{array}{l}\text { At start of monitoring } \\
\mathrm{C} \text { pattern group }\end{array}$ & $73.3(55.1-82.4)$ & $94.1(86.1-98.1)$ & $84.6(63.6-95.1)$ & $88.9(81.3-92.7)$ & 44.0 \\
\hline $\begin{array}{l}\text { After } 24 \mathrm{~h} \text { and } 48 \mathrm{~h} \text { from ROSC } \\
\mathrm{C} \text { pattern group }\end{array}$ & $100(84.8-100)$ & $91.2(84.5-91.2)$ & $83.3(70.7-83.3)$ & $100(92.7-100)$ & - \\
\hline
\end{tabular}

C group, continuous EEG pattern; CI, confidence interval. 

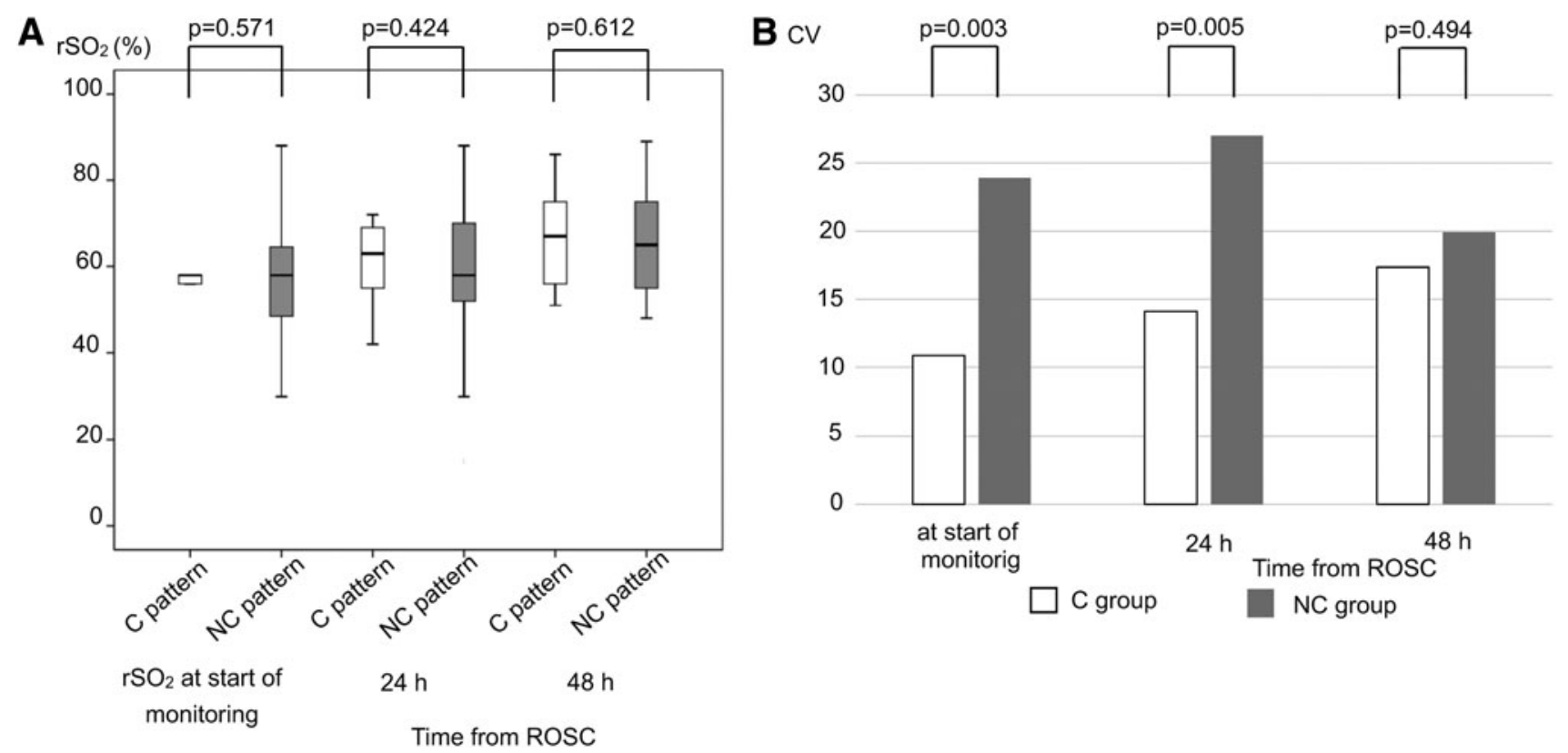

FIG. 3. (A) No significant differences in mean $\mathrm{rSO}_{2}$ values between the $\mathrm{C}$ and $\mathrm{NC}$ groups were observed at each point in time. (B) $\mathrm{CV}=$ standard deviation/mean $\times 100$. $\mathrm{CV}$ for $\mathrm{rSO}_{2}$ in the $\mathrm{NC}$ group was significantly greater than that in the $\mathrm{C}$ group at the start of the monitoring and 24 hours after $\mathrm{ROSC}$. $\mathrm{CV}$, coefficients of variation; $\mathrm{rSO}_{2}$, regional oxygen saturation.

The ESE pattern was reported to be associated with unfavorable outcomes (Rossetti et al., 2007). In this study, patients with ESE at any time point had unfavorable outcomes. However, even in the case of ESE pattern, patients who follow the course of favorable outcomes have been reported (Hovland et al., 2006; Sunde et al., 2006). In reports using aEEG, ESE was reported to be divided into two types (Friberg et al., 2013): a type that changes from a BS pattern to an ESE pattern during the early stage of TTM, and a type that changes from a continuous to an ESE pattern during rewarming to postrewarming. The former type led to an unfavorable outcome, but the latter type may have a favorable outcome. When evaluating ESE, it is important to confirm background EEG and the appearance time of the ESE pattern.

Referring to a study by Storm et al. (2014), in patients with unfavorable outcomes in the early phase after resuscitation from OHCA, a large variation in $\mathrm{SD}$ of $\mathrm{rSO}_{2}$ was observed. In a study on cerebral oxygen saturation in hypoxic ischemic encephalopathy in newborns, the $\mathrm{rSO}_{2}$ value of patients with unfavorable neurological outcomes was wide at the early point in time after birth (Lemmers et al., 2013). However, the study did not consider whether there was a large variation in $\mathrm{SD}$ of $\mathrm{rSO}_{2}$ in patients with unfavorable outcomes. This study also showed that $\mathrm{CV}$ of $\mathrm{rSO}_{2}$ in the $\mathrm{NC}$ group was significantly greater than that in the $\mathrm{C}$ group, although there was no significant difference between $\mathrm{C}$ and $\mathrm{NC}$ patterns at any point in time. Hence, from this fact, the degree of variation in $\mathrm{rSO}_{2}$ values in the $\mathrm{NC}$ group changed more than in the $\mathrm{C}$ group in the early phase after ROSC. As previously mentioned, brain damage in most patients in the $\mathrm{C}$ group must be mild. These facts suggest that if brain damage is severe, the value of $\mathrm{rSO}_{2}$ may widely vary in patients with whole-brain ischemia in the early phase after reperfusion.
Since $\mathrm{rSO}_{2}$ and jugular bulb venous oxygen saturation are correlated (Kim et al., 2000), factors of varying $\mathrm{rSO}_{2}$ are represented by the following formula:

$$
\mathrm{rSO}_{2}=\mathrm{SaO}_{2}-\mathrm{CMRO}_{2} /(\mathrm{CBF} \times 1.34 \times \mathrm{Hb}) .
$$

cerebral blood flow $(\mathrm{CBF})$ is affected by $\mathrm{BP}, \mathrm{PaCO}_{2}$. Parameters of related $\mathrm{rSO}_{2}$ did not vary, except for $\mathrm{Hb}$ at the start of the measurement. Therefore, variation of $\mathrm{Hb}$ at the start of the monitoring may affect $\mathrm{CV}$ of $\mathrm{rSO}_{2}$.

In the normal brain, pressure autoregulation keeps $\mathrm{CBF}$ constant (Kinoshita, 2016). Therefore, in an uninjured brain, even if $\mathrm{BP}$ changes within a certain range, change in $\mathrm{rSO}_{2}$ value is hardly observed. However, in a past report on $\mathrm{CBF}$ in PCAS patients, the pressure autoregulation mechanism was impaired (Sundgreen et al., 2001). Pressure autoregulation in PCAS patients either shifted to the right or was linearly correlated with BP. According to this report, pressure autoregulation in PCAS patients with unfavorable neurological outcomes was impaired and various values of CBF could be observed as BP changes. Another report showed that pressure autoregulation in PCAS patients with unfavorable outcomes was impaired, using NIRSs (Ameloot et al., 2015). In patients with unfavorable neurological outcomes, cerebral oxygen saturation varied along with changes in BP; whereas in patients with favorable outcomes, cerebral oxygen saturation was constant even if BP changed.

In this study, this phenomenon seemed to continue from the start of the measurement to 24 hours, and other studies also showed that this continued at 12 hours (Storm et al., 2014) or 24 hours (Lemmers et al., 2013). Ehara et al. (2017) reported that in cardiac arrest patients with $\mathrm{CPR}, \mathrm{rSO}_{2}$ values significantly increased just after starting extracorporeal cardiopulmonary resuscitation (ECPR) in the poor neurological 
group. On the other hand, cerebral $\mathrm{rSO}_{2}$ values did not increase significantly during ECPR in the good neurological group. One explanation is that impairment of autoregulation in patients with severe brain damage may begin immediately after resuscitation by ECPR and CBF may increase by perfusion of ECPR, leading to an increased $\mathrm{rSO}_{2}$ value.

In this study, $\mathrm{CV}$ of $\mathrm{rSO}_{2}$ was not significantly different between $\mathrm{C}$ and $\mathrm{NC}$ groups 48 hours after ROSC. Pham et al. (2015) reported that 4 out of 14 patients with impaired autoregulation improved over 3 days after ROSC. Consequently, patients in the $\mathrm{NC}$ group with impaired autoregulation may improve 48 hours after ROSC. The cerebral oximetry index $(\mathrm{COx})$ estimates the autoregulation of the brain by using mean arterial pressure and $\mathrm{rSO}_{2}$ (Ameloot et al., 2015). COx is calculated as the linear correlation coefficient by using values of $\mathrm{BP}$ and cerebral oxygen saturation. When $\mathrm{COx}$ shows a positive correlation, it indicates impaired autoregulation of the brain. When COx shows a negative or near-zero correlation, autoregulation of the brain is maintained. Further study to evaluate autoregulation using COx is necessary.

Taken together, more accurate prediction of neurological outcomes by simultaneously monitoring aEEG and $\mathrm{rSO}_{2}$ is considered difficult due to the wide range of obtained $\mathrm{rSO}_{2}$ values in the NC pattern. This fact suggests that autoregulation may be impaired in cases of severe brain damage at the early stage of resuscitation in patients in the NC group.

\section{Limitation}

Many studies on postcardiac arrest patients undergoing hypothermia have also been evaluated for prognosis after 3 to 6 months from ROSC. Because this study assesses neurological outcomes at hospital discharge, it is shorter than the general assessment period. However, there are reports that $\mathrm{CPC}$ at discharge and long-term prognosis on an annual basis are related (Hsu et al., 2014). This article suggests that aEEG pattern, $\mathrm{rSO}_{2}$, and neurological outcome data in this study are informative in regards to prognostic prediction. Further study to examine the relationship between aEEG pattern, $\mathrm{rSO}_{2}$ value, and long-term outcomes is needed.

In our study, $\mathrm{rSO}_{2}$ was measured on the left side of the forehead only, compared with the Storm et al. study, which measured $\mathrm{rSO}_{2}$ average of both sides of the forehead. Toyama et al. (2015) reported no difference between right and left $\mathrm{rSO}_{2}$ values in the measurement of $\mathrm{rSO}_{2}$ by using INVOS during the carotid artery stenting operation. Therefore, we measured left-side $\mathrm{rSO}_{2}$ values only. However, whether there is a left-right difference of $\mathrm{rSO}_{2}$ values is not clear in PCAS patients, and further methodological investigation is required to clarify the difference in results from the Storm study.

\section{Conclusion}

EEG is a useful tool that is used to predict the outcomes of PCAS patients. On the other hand, $\mathrm{rSO}_{2}$ values cannot be used to predict outcome due to the wide range in $\mathrm{rSO}_{2}$ values in PCAS patients with an abnormal aEEG pattern.

\section{Author Disclosure Statement}

No competing financial interests exist.

\section{References}

Ahn A, Yang J, Inigo-Santiago L, et al. A feasibility study of cerebral oximetry monitoring during the post-resuscitation period in comatose patients following cardiac arrest. Resuscitation 2014;85:522-526.

Ameloot K, Genbrugge C, Meex I, et al. An observational nearinfrared spectroscopy study on cerebral autoregulation in post-cardiac arrest patients: time to drop 'one-size-fits-all' hemodynamic targets? Resuscitation 2015;90:121-126.

Bassetti C, Bomio F, Mathis J, et al. Early prognosis in coma after cardiac arrest: a prospective clinical, electrophysiological, and biochemical study of 60 patients. J Neurol Neurosurg Psychiatry 1996;61:610-615.

Callaway CW, Donnino MW, Fink EL, et al. Part 8: postcardiac arrest care: 2015 American Heart Association guidelines update for cardiopulmonary resuscitation and emergency cardiovascular care. Circulation 2015;132:S465-S482.

Cummins RO, Chamberlain DA, Abramson NS, et al. Recommended guidelines for uniform reporting of data from out-of-hospital cardiac arrest: the Utstein Style. A statement for health professionals from a task force of the American Heart Association, the European Resuscitation Council, the Heart and Stroke Foundation of Canada, and the Australian Resuscitation Council. Circulation 1991;84:960-975.

Dragancea I, Rundgren M, Englund E, et al. The influence of induced hypothermia and delayed prognostication on the mode of death after cardiac arrest. Resuscitation 2013;84: 337-342.

Ehara N, Hirose T, Shiozaki T, et al. The relationship between cerebral regional oxygen saturation during extracorporeal cardiopulmonary resuscitation and the neurological outcome in a retrospective analysis of 16 cases. J Intensive Care 2017; 5:20.

Friberg H, Westhall E, Rosen I, et al. Clinical review: continuous and simplified electroencephalography to monitor brain recovery after cardiac arrest. Crit Care 2013;17:233.

Hovland A, Nielsen EW, Kluver J, et al. EEG should be performed during induced hypothermia. Resuscitation 2006;68: 143-146.

Hsu CH, Li J, Cinousis MJ, et al. Cerebral performance category at hospital discharge predicts long-term survival of cardiac arrest survivors receiving targeted temperature management. Crit Care Med 2014;42:2575-2581.

Ibrahim AW, Trammell AR, Austin H, et al. Cerebral oximetry as a real-time monitoring tool to assess quality of in-hospital cardiopulmonary resuscitation and post cardiac arrest care. J Am Heart Assoc 2015;4:e001859.

Kim MB, Ward DS, Cartwright CR, et al. Estimation of jugular venous $\mathrm{O}_{2}$ saturation from cerebral oximetry or arterial $\mathrm{O}_{2}$ saturation during isocapnic hypoxia. J Clin Monit Comput 2000;16:191-199.

Kinoshita K. Traumatic brain injury: pathophysiology for neurocritical care. J Intensive Care 2016;4:29.

Komatsu T, Kinoshita K, Sakurai A, et al. Shorter time until return of spontaneous circulation is the only independent factor for a good neurological outcome in patients with postcardiac arrest syndrome. Emerg Med J 2014;31:549-555.

Lemmers PM, Zwanenburg RJ, Benders MJ, et al. Cerebral oxygenation and brain activity after perinatal asphyxia: does hypothermia change their prognostic value? Pediatr Res 2013;74:180-185.

Meex I, Dens J, Jans F, et al. Cerebral tissue oxygen saturation during therapeutic hypothermia in post-cardiac arrest patients. Resuscitation 2013;84:788-793. 
Nolan JP, Neumar RW, Adrie C, et al. Post-cardiac arrest syndrome: epidemiology, pathophysiology, treatment, and prognostication. A Scientific Statement from the International Liaison Committee on Resuscitation; the American Heart Association Emergency Cardiovascular Care Committee; the Council on Cardiovascular Surgery and Anesthesia; the Council on Cardiopulmonary, Perioperative, and Critical Care; the Council on Clinical Cardiology; the Council on Stroke. Resuscitation 2008;79:350-379.

Pham P, Bindra J, Chuan A, et al. Are changes in cerebrovascular autoregulation following cardiac arrest associated with neurological outcome? Results of a pilot study. Resuscitation 2015;96:192-198.

Reis C, Akyol O, Araujo C, et al. Pathophysiology and the monitoring methods for cardiac arrest associated brain injury. Int J Mol Sci 2017;18.

Rossetti AO, Logroscino G, Liaudet L, et al. Status epilepticus: an independent outcome predictor after cerebral anoxia. Neurology 2007;69:255-260.

Rundgren M, Rosen I, Friberg H. Amplitude-integrated EEG (aEEG) predicts outcome after cardiac arrest and induced hypothermia. Intensive Care Med 2006;32:836-842.

Rundgren $\mathrm{M}$, Westhall $\mathrm{E}$, Cronberg $\mathrm{T}$, et al. Continuous amplitude-integrated electroencephalogram predicts outcome in hypothermia-treated cardiac arrest patients. Crit Care Med 2010;38:1838-1844.

SOS-KANTO 2012 Study Group. Changes in pre- and inhospital management and outcomes for out-of-hospital cardiac arrest between 2002 and 2012 in Kanto, Japan: the SOS-KANTO 2012 Study. Acute Med Surg 2015;2:225-233.
Storm C, Leithner C, Krannich A, et al. Regional cerebral oxygen saturation after cardiac arrest in 60 patients-a prospective outcome study. Resuscitation 2014;85:1037-1041.

Sunde K, Dunlop O, Rostrup M, et al. Determination of prognosis after cardiac arrest may be more difficult after introduction of therapeutic hypothermia. Resuscitation 2006; 69:29-32.

Sundgreen C, Larsen FS, Herzog TM, et al. Autoregulation of cerebral blood flow in patients resuscitated from cardiac arrest. Stroke 2001;32:128-132.

Toyama S, Matsuoka K, Tagaito Y, et al. Retrospective evaluation of the effect of carotid artery stenosis on cerebral oxygen saturation during off-pump coronary artery bypasses grafting in adult patients. BMC Anesthesiol 2015;15:180.

Verrill S, Johnson RA. Confidence bounds and hypothesis tests for normal distribution coefficients of variation. Commun Stat Theory Methods 2007;36:2187-2206

Address correspondence to: Atsushi Sakurai, MD, PhD Division of Emergency and Critical Care Medicine Department of Acute Medicine Nihon University School of Medicine 30-1 Oyaguchikamimachi Itabashi-ku Tokyo 173-8610 Japan

E-mail: sakurai.atsushi@nihon-u.ac.jp 